ure) support an age for the occupation horizon corresponding to the last interglacial $(125,000$ years ago). The hominid is clearly older, perhaps coinciding with the previous interglacial. Our results confirm the view that Peat I and Peat II were separated by an entire landscape cycle and that the hominid remains may relate to an earlier Middle Stone Age industry ${ }^{8}$.

The relatively old age of the hominid fits well with its combination of archaic and modern characteristics, considering that anatomically modern humans are known from several southern African sites from the last interglacial ${ }^{4}$. We are confi-

1. Dreyer, T. F. Argeol. Navors. Nas. Mus., Bloemfontein 1, 65-77 (1938)

2. Brink, J. S. Mem. Nas. Mus., Bloemfontein 24, 151 (1987)

3. Clarke, R. J. in Ancestors: the hard evidence (ed.

Delson, E.) 301-305 (Liss, New York, 1985).

4. Grün, R. \& Stringer, C. B. Archaeometry 33, 153-199 (1991)

5. Grün, R. Quat. Int. 1, 65-109 (1989).

6. Huntley, D. J., Godfrey-Smith, D. I., \& Thewalt, M. L. W. Nature 313, 105-107 (1985)

7. Grün, R. Ancient TL 13, 3-7 (1995).

8. Beaumont, P., de Villiers, H. \& Vogel, J. C. S. Afr. J. Sci. 74, 409-419 (1978). dent that this new method of direct ESR analysis will allow age estimates for further enigmatic hominid fossils such as those from Broken Hill, Skhul and Tabun.

\section{Rainer Grün}

Quaternary Dating Research Centre, Australian National University,

Canberra ACT 0200, Australia

James S. Brink

National Museum, PO Box 266,

9300 Bloemfontein, South Africa

Nigel A. Spooner, Lois Taylor

Division of Archaeology and Natural History, Australian National University,

Canberra ACT 0200, Australia

Chris B. Stringer

Department of Palaeontology,

Natural History Museum,

London SW7 5BD, UK

Robert G. Franciscus

Department of Anthropology,

Stanford University,

California 94305-2145, USA

Andrew S. Murray

Division of Water Resources, CSIRO,

Canberra, ACT 2601, Australia

\title{
Denial of disabilities in anosognosia
}

SIR - A certain proportion of right-hemisphere stroke patients who have left-sided hemiplegia will vehemently deny their paralysis, even though they may be mentally quite lucid in other respects ("denial" or anosognosia $\left.{ }^{1-4}\right)$. We studied three such patients and found, surprisingly, that two of them also refused to acknowledge the paralysis of a fourth patient (or a "stooge") who was in a wheelchair next to them. Thus, in at least some instances, a patient's denial may generalize to include the disabilities of other people's body movements.

All three patients (L.H., F.D. and L.R.; ages 77,77 and 78) were right-handed women with a left hemiplegia. Computed tomography scans confirmed the presence of a subacute right middle cerebral artery and right cerebellar artery infarct in F.D.; a right middle cerebral artery and left cerebellar artery infarct in L.H.; and a right frontoparietal infarct in L.R. At the time of testing, L.R. and F.A. were completely lucid mentally (for example, able to orient in time and place; subtract serial twos; digit span; and so on), fluent in conversation, and of average intelligence. L.H. was also fluent in conversation but her digit span was four. Each patient was asked the following sequence of questions repeatedly: can you walk; can you use both hands; can you use your right hand; can you use your left hand; are both hands equally strong? They were deemed anosognosic only if they answered all questions in the affirmative ${ }^{4}$.

Would an anosognosic patient deny another patients' paralysis? Before each experiment, we first verified the patient was mentally alert and was still in denial as revealed by affirmative answers to the sequence of questions cited above. We then conducted an abbreviated neurological examination on a left-hemiplegic patient in the adjacent wheelchair. (In one case we had to use a student "stooge" pretending to have left hemiplegia.) The wheelchair was in the non-neglected (right) side of the anosognosia patient and was rotated so that the stooge always sat face-to-face with the patient. The patient was then asked carefully to watch the stooge in the wheelchair. From this position, our patient could clearly observe that the stooge's right hand was functioning well but that his left hand was not responding to the examiner's commands.

Immediately after demonstrating the paralysis of the stooges' left hand, each patient was asked "Is that patient moving his arm properly or is he paralysed?" This was done three times in a row and interspersed with brief, irrelevant, distracting questions such as "What do you think of the O. J. trial?" The same experiment was then repeated the following day (L.H. \& F.D.) or a week later (L.R.). On all six trials, both L. H. and F. D. responded without hesitation that the other patient was "OK" and that "he is moving his arm up and down". L.R. seemed very surprised by the question, answering "of course he is paralysed; he is not moving his arm", even though she vehemently denied her own paralysis. It is noteworthy, also, that even when L.R. watched her failure to move her arm in a mirror she continued to insist that she was not paralysed.

Finally, we verified that the patients had no problem with other aspects of their body image, for example, they could name their own as well as other people's body parts (no autotopagnosia) and they could perform skilled movements (for example, touching their nose; waving goodbye; pretending to stir sugar in a cup of tea) with their right hands in response to commands (no apraxia). Nor did they have left parietal or frontal lesions of the kind that might be expected to produce such disturbances. The failures cannot therefore be attributed to simple body-part confusion or to general confusion about limb movements.

We conclude that at least some anosognosic patients will refuse to acknowledge the paralysis of another patient ${ }^{4}$. The observation raises the interesting question of whether the patient needs to believe that the other individual is also a patient. Or, is it the case that some of these patients are unable to access their own body schemata and that such access is necessary even for making judgments about the movements of another human being? Additional experiments are needed to resolve these questions. Certain cells in the monkey frontal lobes ${ }^{5}$ respond not only to their own hand performing certain actions but also to the visual image of another monkey's hand performing the same action: would these cells provide the neural substrate for the delusions experienced by these patients?

\section{S. Ramachandran}

\section{Diane Rogers-Ramachandran}

Brain and Perception Laboratory,

Center for Research on Brain and Cognition 0109 ,

University of California, San Diego,

La Jolla, California 92093, USA

\footnotetext{
1. Babinski, M. J. Revue Neurologique 1, 845-848 (1914).

2. Critchley, M. The Parietal Lobes (Hafter, New York, 1966).

3. Damasio, A. Descartes' Error (Putnam, New York, 1994)

4. Ramachandran, V. S. Conciousness and Cognition 4, 22-51 (1995).

5. Graziano, M. S. A., Yap, G. S. \& Gross, C. Science 226
} 1051-1054 (1994).

\section{Biological activity of interleukin-16}

SIR - Bazan and Schall ${ }^{1}$ implied that the predicted existence of an interleukin-16 (IL-16) precursor protein was evidence that the cloned complementary $\mathrm{DNA}^{2}$ does not represent the originally described native biological activity ${ }^{3}$. But these implications are not supported by our published experimental evidence.

IL-16, formerly known as lymphocyte chemoattractant factor, was identified as a secreted T-cell product that induces motility and interleukin-2-receptor expression in CD4+ T cells; functions that are selectively inhibited by Fab of the OKT4 antibody ${ }^{4}$. IL-16 appears in culture supernatants as a relative molecular mass $\left(M_{\mathrm{r}}\right) \sim 56,000$ biologically active non-covalently linked tetramer, but migrates in monomeric form 